\title{
Topologies for Voltage Sag \& Swell Compensation by Dynamic Voltage Restorer
}

\author{
Sagar P. Joshi ${ }^{1}$, Paresh J. Shah ${ }^{2}$ \\ Research Scholar, Electrical Engineering Dept, SSBT's COET, Bambhori, Jalgaon, India ${ }^{1}$ \\ Professor \& Head, Electrical Engineering Dept, SSBT's COET, Bambhori, Jalgaon, India ${ }^{2}$
}

\begin{abstract}
Power quality has become a considerable issue in modern electrical power system. The extensive use of non linear load has increased the power quality problems such as stability of voltage. The voltage sags \& swells affect the sensitive loads by nuisance tripping of fast acting relays. In order to overcome this power quality problem, dynamic voltage restorer (DVR) is used. The DVR injects the required amount of voltage that is necessary to maintain the system voltage stability during sags \& swells. This paper describes the basic topologies for use of DVR depending up on its location in the power system.
\end{abstract}

Keywords: Dynamic Voltage Restorer, Voltage Sag, Voltage Injection Methods, Control Strategies.

\section{INTRODUCTION}

Power quality problems are associated with large use of non linear load. Power quality problems comprises of broad ranges of time frames such as long duration variations, short duration variations and other disturbances. Short duration variations occur due to either by faulty conditions or energization of large loads having high starting currents. As per IEEE Standard 1159-1995, voltage Sag in defined as decrease of RMS voltage from 0.1 to 0.9 per unit for duration of 0.5 cycles to 1 minute [1]. Voltage stability can be achieved by the use of advanced power electronic device such as dynamic voltage restorer (DVR). DVR's are a class of custom power devices for improvement in power quality. It contains a series of voltage boost technology using solid state switches for compensation of voltage sags/swells [2]. The DVR applications are mainly for sensitive loads that may be drastically affected by fluctuations in system voltage.

DVR is the efficient and effective modern custom power device used in power system. It employs a series of voltage boost technology using solid (static) state switches of 3-phase VSC that injects voltage into the system; to restore the load side voltage for compensating voltage sags/swells, [2]. Other than voltage sags and swells compensation, DVR can also added other features like: line voltage harmonics compensation, reduction of transients in voltage and fault current limitations. As DVR uses energy storage device, it can withstand long duration voltage sag [3].

\section{VOLTAGE SAG}

In transmission or distribution system mostly the voltage sags are the outcomes of short circuit faults. The magnitude of the faulted voltage is given by following equation [5],

$$
\mathrm{U}_{\mathrm{sag}}=\mathrm{E} \frac{\mathrm{Z}_{\mathrm{f}}}{\mathrm{Z}_{\mathrm{f}}+\mathrm{Z}_{\mathrm{s}}}
$$

Where, $\mathrm{U}_{\text {sag }}$ Voltage during Sag at Point of Common Coupling (PCC)

\section{E Supply Voltage \\ $\mathrm{Z}_{\mathrm{f}} \quad$ Impedance at faulted line \\ $\mathrm{Z}_{\mathrm{s}} \quad$ Supply Impedance}

This same equation can be illustrated by following phasor diagram.
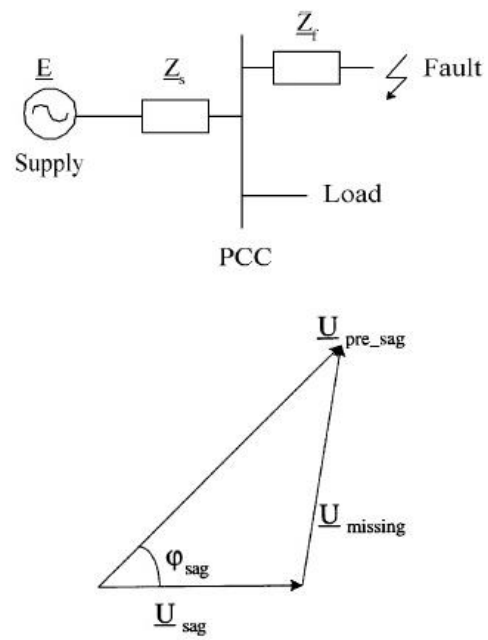

Fig. 1. Voltage Sag Illustration.

The DVR injects the amount of voltage equal to $U_{\text {missing }}$ to cope up the difference in the voltage of faulted line. The voltage sag could be symmetrical or unsymmetrical depending up on the fault on the system.

\section{DYNAMIC VOLTAGE RESTORER}

Voltage sags are the most severe disturbances among the all power quality problems. In order to overcome these problems the concept of custom power devices is introduced recently. DVR is a recently proposed series connected solid state device and is normally installed in a distribution system between the supply and the critical load feeder at the point of common coupling (PCC) [4]. It uses a series of voltage boost technology using solid (static) state switches of 3 phase VSC that injects voltage into the system; to restore the load side voltage for 
compensating voltage sags/swells. In addition to voltage voltage \& sag voltage, maintaining load voltage same as sags and swells compensation, DVR is also useful to that of pre fault voltage [7]. With the use of this method compensate line voltage harmonics, to reduce transients of voltage and fault current limitations too [9].

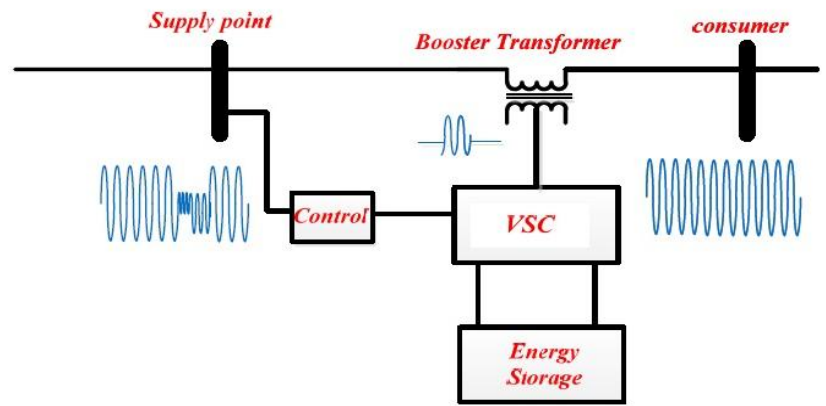

Fig. 2. Basic topology of DVR

The above fig shows the basic construction topology of the dynamic voltage restorer. It consists of the Injecting transformer (also known as boosting transformer), Voltage Source Converter that is responsible for the injection of the power through the energy storage devices either in the form of Capacitors or the Batteries [5].

\section{VOLTAGE INJECTION METHODS}

The rating of the DVR system depends mainly on the depth of the fault voltage that is to be compensated. For voltage sag \& swells with zero phase angle jumps, the requirement of active power of the DVR [6] is given by

$$
P_{D V R}=\left(\frac{V_{1}-V_{2}}{V_{1}}\right) P_{l o a d}
$$

Where, $V_{l} \& V_{2}$ are normal \& faulty line voltages respectively. The active power flowing into DVR charges the DC link. For full compensation of full voltage dip, the rating of the DVR must be as same as that of the DFIG.

There are four voltage injection methods that are normally used as follows.

\section{A. Pre Sag Compensation}

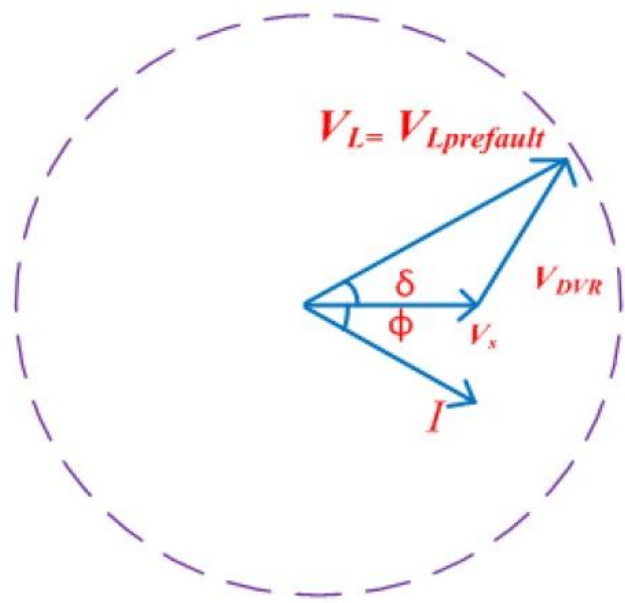

Fig. 3. Pre Sag Compensation Method.

This method is based on technique of constant tracking, where the DVR synchronizes with supply voltage \& if any disturbance in supply voltage detected, it injects the value of voltage that is equal to difference between the supply compensation in both phase angle \& amplitude sensitive loads is achieved. The amount of voltage fed to the system is determined by following expression

$$
V_{d v r}=V_{\text {prefault }}-V_{\text {sag }}
$$

\section{B. In Phase Compensation Method}

The voltage that is to be injected is in phase with the supply voltage irrespective of the pre sag value [8]. By this method the constant amplitude of the load voltage is maintained. The advantage with this method is that the amplitude of DVR injection voltage is less for the voltage sag condition, as compared with other topologies [6].

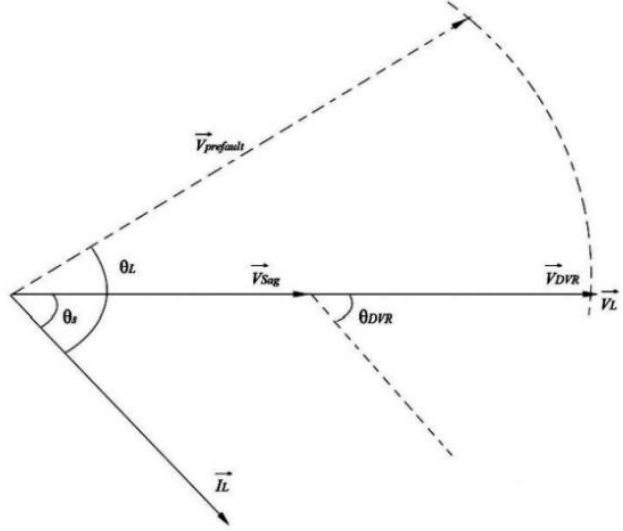

Fig. 4 In Phase Compensation Phasor Diagram.

\section{In Phase Advanced Compensation}

This method is based on the phase angle compensation. The phase angle of voltage sag \& the load current is minimized to control the real power supplied. In previous two methods, the active power is injected into system during disturbances. So this method is economical over rest of the methods. The values of load currents \& voltages are fixed the change is done in only phase angle of the voltage sag. So reactive power is being used by this method, but not all voltage sags are mitigated by this system hence it is suitable for only limited range of voltage sags.

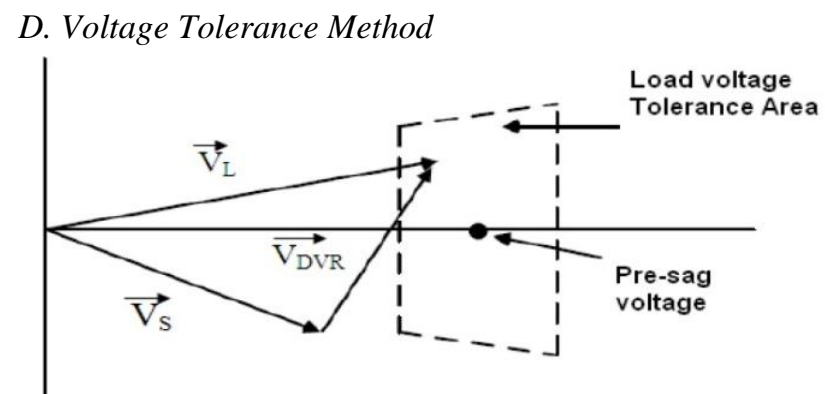

Fig. 5. Voltage Tolerance Method Phasor Diagram.

This method deals with setting the values of voltages in range with which it will maintain the system under normal operation. There always exists some tolerable limit in the system. Similarly, small amount of voltage drop \& phase angle jump is allowable in the system. If the voltage magnitude lies in between the range of $90-110 \%$ of 
nominal voltage \& 5-10\% of nominal state that will not The power ratings of the two converters are distinct, since affect the performance characteristics of the load [6]. the power handled by the series converter is directly Hence both magnitude \& phase are the control parameters, proportional to the faulty line voltage \& the maximum which can be achieved by this method of small energy injection. Ultimately small energy storage device will be required for this of topology.

\section{CONTROL STRATEGIES FOR THE OPERATION OF DVR}

DVRs operate to maintain the load supply voltage at its rated value. The systems considered in this paper are all three-phase, and only active power flow is considered in the analysis of their rating requirements. During voltage sag, the DVR injects a voltage to restore the load voltages. Here, the real \& reactive power is exchanged with the existing power system. For the active power supplied to the load from the DVR, it needs a source for this energy.

It can utilize either separate energy source or use the system voltage without using separate energy storage. For the system using energy storage, we can use different kinds of systems such as batteries, capacitors, flywheel, or Super Magnetic Energy Storage (SMES) [5]. For the nostorage topology, the DVR has to take voltage from the faulted grid supply during the sag. Four DVR topologies are considered in this paper as follows.

\section{A. DVR Topologies without Energy Storage}

This technique uses the system supply to compensate the faulty line voltage. So the supply used as the source to compensate the line voltage during voltage sag will also have the same magnitude of the voltage sag $\&$ the shunt converter will charge the DC link first with that supply \& the required value of voltage will be supplied by the system to compensate faulty line voltage [5]. But this system has drawback that system load current will increase during fault condition, so higher value of current will flow through the energy storage system \& it will create the voltage drop for the upstream loads. It also gives savings in the energy \& the ability to compensate longer sags. A passive shunt converter is used to allow the flow of power in only one direction.

\section{1) Supply Side-Connected Shunt Converter}

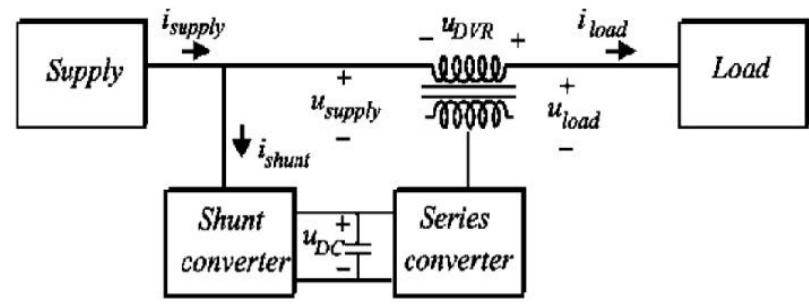

Fig. 6. Supply Side Connected Shunt Converters

This system contains an uncontrollable dc-link voltage. The passive converter charges the dc-link capacitor to the actual state of the supply voltage. The dc-link voltage becomes nearly equal to the supply voltage hence; during voltage sags the dc-link voltage also drops in proportion to the sag voltage. voltage and current loadings of the shunt converter do not occur simultaneously, as the current drawn by the shunt converter rises significantly during severe sags as its input voltage reduces [5]. Hence, the ability to compensate for deep voltage sags will be limited as the dc-link voltage in the topology follows the line voltage down and the voltage available for compensation becomes limited. This type of system is useless when the supply voltage is subjected to unsymmetrical voltage sag.

\section{2) Load-Side-Connected Shunt Converter}

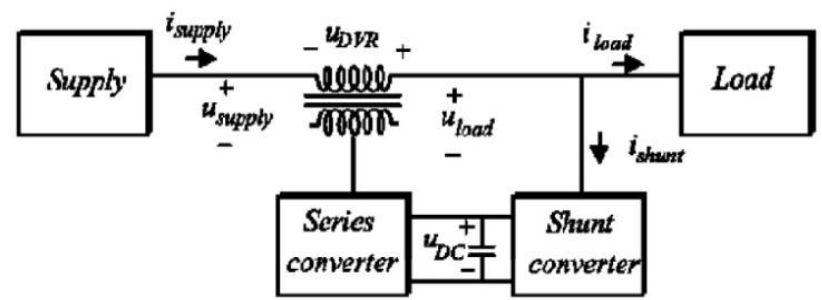

Fig. 7. Load Side Connected Shunt Converter

The system having load side connected Shunt Converter has the input voltage controlled by the virtue of constant supply injected by series converter so, DC Link voltage can be maintained constant. This topology has the disadvantage of larger currents to be handled by the series converter. If the supply voltage falls then at rated load the current through the series converter is much higher followed by the moderately high current through the shunt converter [5]. In addition, the load can be disturbed by the nonlinear currents drawn by the passive shunt converter. This topology is useful for compensation of long duration voltage sags.

\section{B. DVR Topologies with Energy Storage}

Maintaining a system equipped with separate energy storage device is somewhat expensive but reliable. Storing electrical energy is expensive, but for certain types of voltage sags the performance of the DVR can be improved and the strain on the grid connection is lower.

\section{1) Variable DC-Link Voltage}

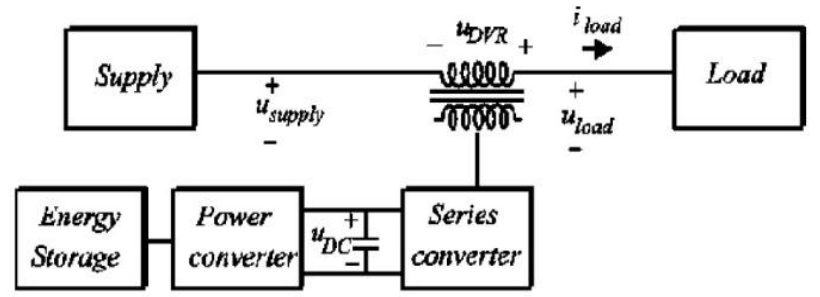

Fig. 8: Energy Storage with DC Link Capacitors

This topology is operated with a variable dc-link voltage. Here, the stored energy is proportional to the square of the rated dc-link voltage [5] as shown in the following expression,

$$
E_{\text {storage }}=\frac{1}{2} C_{D C} V_{D C}^{2}
$$


Where, $E_{\text {storage }}$ is Energy that is stored in the energy storage system, $\mathrm{C}_{\mathrm{DC}}$ is the $\mathrm{DC}$ link capacitance \& $\mathrm{V}_{\mathrm{DC}}$ is the DC link voltage.

The voltage decays exponentially during a sag compensation \& as the dc-link voltage decays the ability to compensate severe sags deteriorates. Hence, this topology has drawback that it can be used up to certain voltage level, as given by following expression,

$$
\Delta E=\frac{1}{2} C_{D C}\left(V_{D C, \text { Begin }}^{2}-V_{D C, \text { End }}^{2}\right)
$$

Where, $\mathrm{V}_{\mathrm{DC} \text {,Begin }}$ is the value of voltage at just beginning of the voltage sag, $\mathrm{V}_{\mathrm{DC} \text {,End }}$ is the value of voltage at just end of the voltage sag.

Thus due to use of separate energy storage medium, this type of topology is of no use when voltage sag lasts for long duration.

\section{2) Constant DC-Link Voltage}

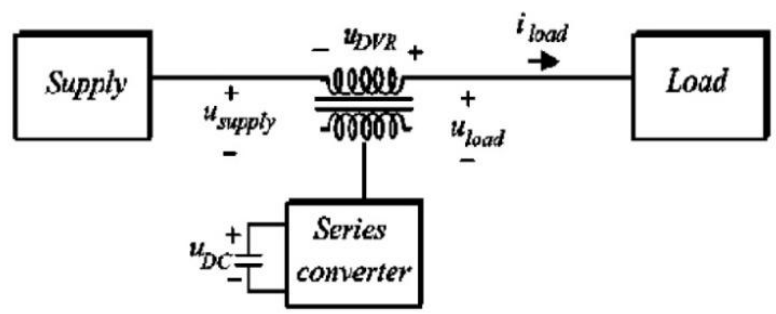

Fig. 9: Energy Storage with Const DC Link Voltage

Direct energy storage methods, such as SMES, batteries or super capacitors, can be used in a DVR by adding a separate heavy duty converter to the system. So, energy is then transferred from large storages to a smaller rated dclink storage using this converter during the sag. Hence, the DC voltage is held almost constant. So, the system is robust for feeding deep voltage sags along with non symmetrical voltage sag. This specific arrangement gives the improvement in the system but ultimately cost of the system increases.

\section{CONCLUSION}

This paper describes four numbers of topologies for the operation of DVR. The approach contains the absence of energy storage along with particular location that is when connected at supply end and at load end and secondly the approach with use of energy storage having variable DC link voltage \& constant DC link voltage. The system with absence of energy storage is proven best for the faults with long voltage sag duration whereas it has lower performance for non symmetrical voltage sag. For the system with energy storage it shows improved performance at the time of non symmetrical voltage sags $\&$ lesser performance for the long duration voltage sags. For conclusion among all these systems the system with load side connected passive filter is proven best.

\section{REFERENCES}

[1] P. J. Shah, Rakesh Saxena, M. P. S. Chawla, "Various techniques for improving the power quality in power supplies," IEEE international conference on computational intelligence, communication systems and networks (CICSyN 2009), Indore, Madhya Pradesh, July 2009
[2] Christian Wessels, Fabian Gebhardtand, Friedrich Wilhelm Fuchs, "Fault Ride-Through of a DFIG Wind Turbine Using a Dynamic Voltage Restorer During Symmetrical and Asymmetrical Grid Faults," IEEE Transactions On Power Electronics, Vol. 26, No. 3, March 2011.

[3] Gauri S. Sarode, Dr. P. J. Shah, Dr. Rakesh Saxena, "Overview of Interline Dynamic Voltage Restorer for Power Quality Improvement," Australian Journal of Information Technology and Communication Vol.2 No. 1, eptember/October 2005.

[4] F. Mohammad Mahdianpoor, Rahmat Allah Hooshmand, Mohammad Ataei "A New Approach to Multifunctional Dynamic Voltage Restorer Implementation for Emergency Control in Distribution Systems," IEEE Transactions on Power Delivery, Vol. 26, No. 2, April 2011.

[5] John Godsk Nielsen, Frede Blaabjerg, "A Detailed Comparison of System Topologies for Dynamic Voltage Restorers," IEEE Transactions on Industry Applications, Vol. 41, No. 5, September/October 2005.

6] Mayank Paliwal, Rohit Chandra Verma, Shaurya Rastogi, "Voltage Sag Compensation Using Dynamic Voltage Restorer," Advance in Electronic and Electric Engineering, Vol. 4, No. 6, 2014.

[7] M.Sharanya, B.Basavaraja , M.Sasikala, "An Overview of Dynamic Voltage Restorer for Voltage Profile Improvement," International Journal of Engineering and Advanced Technology (IJEAT), Vol. 2, No. 2, December 2012

[8] Abdul Mannan Rauf, Vinod Khadkikar, "An Enhanced Voltage Sag Compensation Scheme for Dynamic Voltage Restorer," IEEE Transactions on Industrial Electronics, Vol. 62, No. 5, May 2015.

[9] S.F. Torabi, D. Nazarpour, Y. Shayestehfard, "Compensation of Sags and Swells Voltage Using Dynamic Voltage Restorer (DVR) During Single Line to Ground and Three-Phase Faults," International Journal on Technical and Physical Problems of Engineering (IJTPE), Vol. 4, No. 3, Sep. 2012.

[10] Shakti Prasad Mishra, Bishnupriya Biswal, J Preetha Roselyn, D. Devraj, "Simulation \& analysis of DVR for mitigating voltage sags \& swell", International Conference of Design \& Manufacturing, Science Direct, 341-350. 